DOI

http://dx.doi.org/10.15448/1983-4012.2015.2.18945

\title{
UMA TEORIA DA JUSTIÇA DE JOHN RAWLS E SEUS CRÍTICOS
}

A theory of justice by John Rawls and its critics

Ubiratan Trindade *

Resumo: Neste breve ensaio, pretendo atualizar o tema da justiça a partir da obra Uma teoria da justiça (2002) de John Rawls, mostrando sua relevância para o debate atual no que diz respeito a valores substanciais, tais como a liberdade, igualdade e democracia. Vou analisar as críticas sofridas por Rawls, originadas por pensadores libertários e comunitaristas, tais como Nozik, Michael Sandel e Charles Taylor. Vou refletir sobre o contratualismo na perspectiva crítica de Hegel e por fim, mostrar que o necontratualismo, tal como proposto por Rawls, tem um forte sentido igualitário e corresponde às necessidades das sociedades democráticas contemporâneas.

Palavras-chave: Liberdade. Democracia. Contratualismo. Neocontratualismo.
Abstract: In this brief essay, I intend to update the theme of justice starting from the composition by John Rawls, A Theory of Justice (2002), presenting its relevance to the current debate in terms of substantial amounts, such as freedom, equality and democracy. I will analyse the critics suffered by Rawls, originated by libertarian and communitarian thinkers, such as Nozik, Michael Sande and Charles Taylor. I will reflect about the contractualism in Hegel's critical perspective and ultimately, show that the neo-contractualism as proposed by Rawls, has a deep egalitarian sense and corresponds to the needs of contemporary democratic societies. Keywords: $\quad$ Freedom. Democracy. Contractualism. Neo-contractualism.

* Doutorando no PPGF - Programa de Pós-graduação em Filosofia da Unisinos - Universidade do Vale do Rio dos Sinos. Email: trindadeumi@gmail.com

\begin{tabular}{|c|c|l|l|c|c|}
\hline intuitio & $\begin{array}{c}\text { ISSN } \\
1983-4012\end{array}$ & Porto Alegre & Vol.8 $-\mathrm{N}^{\mathrm{o}} .2$ & $\begin{array}{c}\text { Dezembro } \\
2015\end{array}$ & p.66-75 \\
\hline
\end{tabular}




\section{A teoria da justiça de John Rawls}

Rawls afirma que as instituições básicas da sociedade não devem se distinguir apenas por serem organizadas e eficientes: elas devem ser, sobretudo, justas. E, se não forem, então deverão ser reformuladas ou abolidas. No capítulo I, de Uma teoria da justiça (2002) quando trabalha a justiça como equidade, Rawls deixa claro que a justiça é a primeira virtude das instituições sociais, como a verdade o é dos sistemas de pensamento. Embora elegante e econômica, uma teoria deve ser rejeitada ou revisada se não é verdadeira ${ }^{1}$. A partir desse critério, Rawls orienta boa parte de seu trabalho para responder às questões de como propor uma sociedade bem ordenada. A preocupação do filósofo de Baltimore era ocupar o lugar de outras concepções teóricas, que afirmavam ter uma resposta às questões de justiça social e que predominavam na tradição filosófica. Entre as teorias em destaque mais aceitas, estava o utilitarismo. Rawls não se dava satisfeito com a aplicação prática da teoria defendida por John S. Mill ${ }^{2}$, quando utilizava o termo relacionado à sociedade que queria fundar ou até mesmo por Jeremy Bentham, quando projetou fundar uma seita chamada The cect of Utilitarians ${ }^{3}$.

De modo geral, o utilitarismo designa a doutrina segundo aquela postura que considera um ato como correto quando maximiza a felicidade geral. A melhor opção, de acordo com o utilitarismo, é a que mais contribui para o bem-estar geral. Rawls rejeita o utilitarismo em seu aspecto de concepção teleológica ou consequencialista, procurando demonstrar, que tal teoria moral, não corrige as injustiças presentes na sociedade. Em uma sociedade orientada por princípios de justiça, como a proposta por Rawls, imagina-se que os agentes racionais, em uma situação de igualdade, rejeitariam o utilitarismo. Parece pouco provável que pessoas que se veem como iguais, com direito a fazer exigências mútuas, concordariam com um princípio que pode exigir para alguns, expectativas de vida inferiores, simplesmente por causa da uma soma maior de vantagens desfrutadas por outros ${ }^{4}$. O desafio teórico representado pelo utilitarismo tem sido, em geral, muito mais sério do que podemos imaginar. De fato, implícita ou explicitamente, muitos de nos tendemos a favorecer soluções utilitaristas quando temos dúvidas sobre como decidir algum dilema moral. Por exemplo, tendemos a preferir as decisões que beneficiam uma maioria de pessoas quando não sabemos como decidir um certo caso; tendemos a considerar como aceitáveis aquelas políticas orientadas a promover o bem-estar geral. Agimos de modo "consequencialista" quando, com a finalidade de avaliar determinado curso de ação, examinamos o modo como tal ação contribui para a obtenção de um estado de coisas que consideramos intrinsecamente bom ${ }^{5}$.

\footnotetext{
${ }^{1}$ RAWLS, John. Justiça e democracia. São Paulo: Martins Fontes, 2002, p. 4.

${ }^{2}$ MILL, John Stuart. Utilitarismo. Coimbra: Biblioteca filosófica, 1961.

${ }^{3}$ MORA, J. Ferrater. Dicionário de Filosofia. São Paulo: Edições Loyola, 2001. P. 2959.

${ }^{4}$ RAWLS, John. Justiça e democracia. São Paulo: Martins Fontes, 2002, p. 15.

${ }^{5}$ GARGARELLA, Roberto. As teorias da justiça depois de Rawls: um breve manual de filosofia política. São Paulo:
}

\begin{tabular}{|c|c|c|c|c|c|}
\hline intuitio & $\begin{array}{c}\text { ISSN } \\
1983-4012\end{array}$ & Porto Alegre & Vol.8 $-\mathrm{N}^{\circ} .2$ & $\begin{array}{c}\text { Dezembro } \\
2015\end{array}$ & p.66-75 \\
\hline
\end{tabular}


No nível social, o utilitarismo é visto como um corpo, no qual seria possível sacrificar algumas partes em virtude das restantes. Rawls rejeita a ideia de impor sacrifícios a um determinado setor da sociedade, com o único objetivo de melhorar a vida dos demais. Acrescenta, que uma proposta como a apresentada pelo utilitarismo, não seria capaz de encontrar apoio em uma situação contratual hipotética, tal como o artifício de representação da posição original na teoria da justiça.

\section{O contratualismo de Rawls}

O contratualismo ocupa um lugar muito especial na teoria da justiça de John Rawls. Seu liberalismo político, eleva ao mais alto nível a autonomia da pessoa. É razoável imaginarmos, que em uma situação de escolha, todas as pessoas envolvidas no processo e que possam ser afetadas por tais decisões, devam ser consultadas. Em linhas gerais, podemos afirmar que a especial importância do contratualismo deve-se ao fato de nos ajudar a responder a duas perguntas básicas envolvidas em qualquer teoria moral: (i) O que a moral exige de nós? E, (ii) por que devemos obedecer à certas regras? No que diz respeito à primeira pergunta, o contratualismo observa que a moral exige que cumpramos aquelas obrigações que nos comprometemos a cumprir. Quanto à segunda interrogação, o contratualismo afirma que a razão pela qual devemos obedecer à certas regras é porque nos comprometemos a fazer isso. Estas eram no medievo, por exemplo, questões relacionadas à religião e que, com o advento da razão e do iluminismo já não correspondiam mais aos fatos. Como o jusnaturalismo também não ofereceu todas as respostas à questão do poder e do Estado, o contratualismo apresentou-se para preencher o vazio deixado pelas explicações religiosas e naturais sobre as questões morais e sobre o problema da autoridade. O poder, na modernidade, passa a ser uma construção dos próprios indivíduos, não podendo ser mais justificado por entidades metafísicas ou transcendentais. Na teoria da justiça como equidade defendida por Rawls, ele imagina um contrato hipotético, um acordo que firmaríamos sob condições ideais e no qual é respeitado nosso caráter de seres livres, racionais e iguais. Seu contrato é relevante porque reflete nosso status moral igual, ou a ideia de que, de um ponto de vista moral, o destino de cada um tem a mesma importância, ou seja, a ideia de que todos nos equivalemos. O contrato em questão serve para construir a ideia de que nenhuma pessoa está subordinada às demais, diferente do contrato hobbesiano, por exemplo, que determina que para superar nossas desigualdades naturais, temos que transferir nossos poderes a um terceiro, o soberano.

Cabe destacar que o contrato tal como proposto por Rawls tem como objetivo estabelecer princípios últimos de justiça. Esses princípios não visam resolver casos particulares ou problemas cotidianos. Os princípios defendidos por Rawls surgem como critérios que se destinam a ser aplicados à estrutura básica da sociedade. Com a palavra o filósofo: o objeto primário da justiça é a estrutura básica

WMF Martins Fontes, 2008, p. 4.

\begin{tabular}{|c|c|c|c|c|c|}
\hline intuitio & $\begin{array}{c}\text { ISSN } \\
1983-4012\end{array}$ & Porto Alegre & Vol.8 $-\mathrm{N}^{\circ} .2$ & $\begin{array}{c}\text { Dezembro } \\
2015\end{array}$ & p.66-75 \\
\hline
\end{tabular}


da sociedade ou, mais exatamente, o modo como as instituições sociais mais importantes distribuem os direitos e deveres fundamentais, e determinam a divisão das vantagens provenientes da cooperação social. Assim, a Constituição política, as formas legalmente reconhecidas de propriedade, a organização da economia e a natureza da família fazem parte da estrutura básica ${ }^{6}$.

A escolha dos princípios de justiça acontece em condições procedimentais de imparcialidade tendo como resultado um sistema de justiça como equidade. Nesse sistema, considera-se que os princípios de justiça são os que resultariam de uma escolha realizada por pessoas livres, racionais e não egoístas colocadas em uma posição de igualdade e de imparcialidade. Para desenvolver sua tese, Rawls recorre ao artifício da posição original, o mesmo que o estado de natureza nas teorias contratualistas. Para chegar aos princípios desejados, algumas condições são indispensáveis aos agentes que farão suas escolhas. A intuição de Rawls é a de que nessa situação hipotética, a escolha dos princípios morais não ficaria subordinada às nossas situações particulares, nossos desejos, impulsos ou inclinações. Para impedir a influência indevida das circunstâncias ou contingências de cada um, Rawls propõe o artifício do véu de ignorância que impede que cada um conheça sua classe ou status social, as capacidades naturais, sua força e sua inteligência. Também não conhecem sua concepção de bem e até mesmo suas características psicológicas. A despeito de tudo, resta a estas pessoas a possibilidade de reconhecerem certas proposições gerais que são fundamentais para a organização da sociedade. O que é impedido às partes, são aqueles procedimentos que levam somente em consideração o favorecimento pessoal. Assim, na posição original, sob um véu de ignorância, as partes fazem um pacto, ou um acordo capaz de considerar imparcialmente os pontos de vista de todos os participantes.

Rawls supõe que os agentes estão motivados a obter certos tipos de bens que ele denomina de bens primários. Os bens primários são aqueles que são indispensáveis para satisfazer um plano de vida boa. Estes bens são de dois tipos: (i) os bens primários de característica social que são distribuídos pelas instituições sociais tais como riquezas, oportunidades e direitos e (ii) os bens primários naturais que são próprios de cada um tais como inteligência, saúde ou talentos. O procedimentalismo rawlsiano, determina que as partes em uma situação de igualdade, na posição original, condicionadas ao véu de ignorância, encontram-se em condições propícias para a escolha dos princípios que irão dar sustentação à uma sociedade bem ordenada. Rawls entende que em tais condições, pessoas racionais, livres e iguais, utilizando-se do procedimento do equilíbrio reflexivo, chegariam ou teriam como resultado de suas deliberações a escolha dos seguintes princípios de justiça: a) Cada pessoa tem um direito igual ao sistema mais amplo de liberdades fundamentais que seja compatível com um sistema similar de liberdades para todos; b) as desigualdades sociais e econômicas são aceitáveis desde que (i) sejam estabelecidas para o maior benefício dos menos privilegiados e (ii) estejam vinculadas a posição e cargos abertos a todos em

${ }^{6}$ RAWLS, John. O liberalismo politico. (Tradução: Álvaro Vita) São Paulo: Martins Fontes, 2011, p. 305.

\begin{tabular}{|c|c|l|l|c|c|}
\hline intuitio & $\begin{array}{c}\text { ISSN } \\
1983-4012\end{array}$ & Porto Alegre & Vol.8 $-\mathrm{N}^{\mathrm{o}} .2$ & $\begin{array}{c}\text { Dezembro } \\
2015\end{array}$ & p.66-75 \\
\hline
\end{tabular}


condições de igualdade equitativa de oportunidades ${ }^{7}$. O primeiro princípio indica que, sob qualquer hipótese, os agentes não podem ser discriminados pelas instituições que fazem parte da estrutura básica da sociedade. É importante salientar que Rawls se refere aqui, às liberdades civis e políticas próprias das democracias modernas ${ }^{8}$. O segundo princípio, também conhecido como princípio da diferença, é o que governa a distribuição dos recursos econômicos e todas as riquezas produzidas na sociedade. Se o primeiro princípio está vinculado à ideia de liberdade, o segundo está associado à ideia da igualdade e da distribuição de renda na estrutura básica da sociedade. O princípio da diferença tal como aparece na teoria de Rawls, implica a superação de uma ideia de justiça distributiva tal como acontece nas sociedades modernas mais igualitárias, segundo a qual o que cada um obtém é justo se os benefícios ou posições em questão também forem acessíveis aos demais.

É importante destacar, que a teoria de Rawls não elimina as diferenças naturais e os talentos particulares que acontecem no interior de uma sociedade qualquer. Também, não se satisfaz com uma mera igualdade de oportunidades. Afirma sim, que as maiores vantagens dos mais beneficiados pela loteria natural só são justificáveis se fizerem parte de um esquema que melhore as expectativas dos membros menos favorecidos da sociedade. É no ponto de partida que sua teoria constrói um forte vínculo com a igualdade. Na posição original, as partes desconhecem os traços básicos de sua biografia, sendo que isto é fundamental para o critério de imparcialidade na hora da escolha. É forte em Rawls a ideia de que uma teoria da justiça não merece ser reconhecida como tal se permite que as pessoas sejam beneficiadas ou prejudicadas por circunstancias alheias a sua vontade. O pensamento igualitário de Rawls nos conduz a refletir sobre fatos arbitrários e fatos pelos quais alguém é plenamente responsável. Os fatos arbitrários de um ponto de vista moral - fatos alheios à responsabilidade de cada um - como, por exemplo, nascer em uma família rica ou pobre, viver em um ambiente com muitos estímulos culturais ou poucos estímulos culturais, independem de cada um. Situações como as citadas, são arbitrarias do ponto de vista moral, dado que os indivíduos que são beneficiados ou prejudicados, não fizeram nada para merecer tal sorte ou tal azar. São fatos que se devem exclusivamente à loteria natural, aos acasos da natureza. Uma sociedade justa deve na medida do possível, igualar as pessoas no ponto de partida, deixando a cada indivíduo a oportunidade de fazer suas escolhas particulares no decorrer de sua vida.

\section{A crítica libertária}

\footnotetext{
${ }^{7}$ RAWLS, John. O liberalismo politico. (Tradução: Álvaro Vita) São Paulo: Martins Fontes, 2011, p. 321.

${ }^{8}$ GARGARELLA, Roberto. As teorias da justiça depois de Rawls: um breve manual de filosofia política. São Paulo: WMF Martins Fontes, 2008, p. 24.
}

\begin{tabular}{|c|c|c|c|c|c|}
\hline intuitio & $\begin{array}{c}\text { ISSN } \\
1983-4012\end{array}$ & Porto Alegre & Vol.8 $-\mathrm{N}^{\mathrm{o}} .2$ & $\begin{array}{c}\text { Dezembro } \\
2015\end{array}$ & p.66-75 \\
\hline
\end{tabular}


A teoria política de Rawls sofreu várias críticas, procedentes de pensadores libertários e comunitaristas. Da vertente dos libertários, também conhecidos como liberais clássicos, Robert Nozick ${ }^{9}$ é um dos principais ideólogos da política contrária ao Estado de bem-estar social podendo ser classificado como um individualista atomista ultraliberal e um dos mais ferrenhos críticos ao Estado social proposto por Rawls. Rawls é claramente um liberal de pendor mais moderno do que clássico (Barry, 1973). Os liberais clássicos (Locke, Stuart Mill, Adam Smith e Humboldt) tem a tendência de diminuir o tamanho do Estado. Já os liberais modernos (escola keynesiana) ${ }^{10}$ admitem uma maior presença do Estado em nossas vidas. Para os liberais modernos entre os quais podemos incluir o próprio Rawls, o Estado deve preocupar-se com questões como a pobreza, habitação, doença, saúde e educação da população. A crítica feita à Rawls por Nozick está bem presente na obra Anarchy, State and Utopi.(1974). Nozick é um notável liberal clássico que, baseado em princípios, propõe um Estado que regule o mínimo possível a vida das pessoas. Segundo ele, a teoria proposta por Rawls interfere em demasia nas questões dos indivíduos.

Em defesa de seu Estado mínimo Nozick afirma que os indivíduos possuem direitos sendo que, há coisas que nenhuma pessoa ou grupo pode fazer-lhes sem violá-los. Entre estes direitos estão o direto de liberdade pessoal e de propriedade privada. A defesa de Nozick está muito próxima do estado de natureza concebido pelo filosofo inglês do século XVII, John Locke. A teoria de Locke afirma que "indivíduos no estado de natureza vivem num estado de perfeita liberdade de determinação de suas ações e dispõe dos seus bens e pessoas como acham adequado, dentro dos limites das leis naturais, sem pedirem autorização

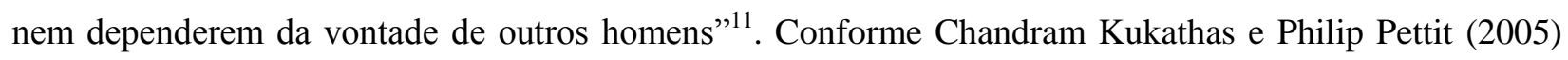
um libertário que assuma a concepção de direitos partilhada por Nozick enfrenta um grande problema quando é perguntado sobre o melhor sistema sócio-político. A alternativa que lhes resta é denunciar qualquer Estado, por mínimo que seja, embora, na teoria de Nozick exista um lugar para o Estado, mesmo que seja mínimo.

Nozick identifica dois pontos vulneráveis na teoria de Rawls: a primeira objeção colocada é que no ponto de partida, os bens sempre pertencem a alguém. As coisas chegam ao mundo, ligadas às pessoas que tem direitos sobre elas. Não existiria questão de justiça ou valores morais. Nozick combate fortemente a ideia, de um modelo de justiça distributiva, como a sugerida por Rawls. Já, para Rawls, os bens são tratados como questão de justiça sendo que os mesmos em uma posição original não pertencem a ninguém. O segundo ponto vulnerável da teoria de Rawls, destacado por Nozick, fala sobre a objeção prática. A teoria de Rawls com seu ideal estrutural de justiça é utilizada para regular a sociedade sendo

\footnotetext{
${ }^{9}$ Robert Nozick (1938-2002) foi um filósofo norte-americano e professor da Universidade Harvard.

${ }^{10}$ John Maynard Keynes (1883-1946) foi um economista britânico cujos ideais serviram de influência para a macroeconomia moderna. A teoria atribuiu ao Estado o direito e o dever de conceder benefícios sociais que garantam à população um padrão mínimo de vida.

${ }^{11}$ NOZICK, Robert. Anarchy, State and Utopia. Nova Iorque: Basic Books, 1974, p. 10.
}

\begin{tabular}{|c|c|l|l|c|c|}
\hline intuitio & $\begin{array}{c}\text { ISSN } \\
1983-4012\end{array}$ & Porto Alegre & Vol.8 $-\mathrm{N}^{\circ} .2$ & $\begin{array}{c}\text { Dezembro } \\
2015\end{array}$ & p.66-75 \\
\hline
\end{tabular}


que seria intolerável o Estado interferir demais na vida e nos atos das pessoas. Mais precisamente Nozick, prefere um Estado que interfira o mínimo possível na vida econômica das pessoas, fazendo uma objeção clara ao princípio da diferença proposto em Uma teoria da justiça, o qual assegura que, as eventuais desigualdades econômicas na distribuição de renda e riqueza, somente são aceitáveis caso beneficiem os menos favorecidos.

\section{A crítica comunitarista}

O conjunto de críticas mais importantes veio dos comunitaristas, encabeçados por Michael Walzer, Alasdair MacIntyre, Charles Taylor e seu maior oponente, Michael Sandel. De acordo com os comunitaristas, modelos liberais como o de Rawls tendem a conceber o indivíduo isolado da comunidade e de suas ideias correlatas de bem comum, tradição e contexto, tornando-o incapaz de assegurar a coesão e integração de um grupo social qualquer, menos ainda da sociedade como um todo, que sempre precede o indivíduo $^{12}$. Sandel (1982), como os demais comunitaristas, acredita que os princípios morais só podem ser compreendidos através das práticas que prevalecem em sociedades reais. Para os comunitaristas a moralidade é algo que está enraizada nas práticas particulares das comunidades. Sendo assim, seria impraticável a ideia de revelar princípios abstratos de moralidade para avaliar ou repensar as sociedades existentes. Uma sociedade procedimental aos moldes de Rawls e sua posição original, geraria indivíduos isolados e sem vínculos patrióticos. A questão que fica para os comunitaristas, principalmente para Sandel, é como encontrar princípios de justiça social que poderiam comandar a submissão voluntária de todas as pessoas racionais, até de pessoas com perspectivas bastante diferentes sobre a vida boa. Sob as circunstâncias de uma ontologia social, a posição moral ou política adotada, é diferente do ponto de vista dos liberais e comunitaristas. Enquanto os liberais (atomistas) dão primazia aos direitos individuais e às liberdades, os comunitaristas (holistas) dão maior prioridade à vida comunitária ou ao bem das coletividades $^{13}$.

Na obra Liberalism and the Limits of justice (1982), Michael Sandel oferece-nos uma crítica à filosofia política de Rawls e ao pensamento liberal em geral. Sandel não aceita a explicação de pessoa introduzida por Rawls na posição original. Neste artifício de representação é pedido às partes que escolham princípios de justiça que seriam segundo Rawls os princípios justos para fundar uma sociedade bem-ordenada. Para Sandel, seria difícil aceitar, como propôs Rawls, a explicação da pessoa como sujeito moral, suficientemente desligado de sua vida real na hora da escolha de tais princípios. O conceito de pessoa e sua constituição ou sua identidade seria abstrato e totalmente desvinculado do mundo real. Um

\footnotetext{
${ }^{12}$ OLIVEIRA, Nythamar Fernandes de. RAWLS. Rio de Janeiro: Zahar Editora, 2003, p. 22.

${ }^{13}$ TAYLOR, Charles. Argumentos filosóficos. São Paulo: Edições Loyola, 2000, p. 198.
}

\begin{tabular}{|c|c|c|c|c|c|}
\hline intuitio & $\begin{array}{c}\text { ISSN } \\
1983-4012\end{array}$ & Porto Alegre & Vol.8 $-\mathrm{N}^{\mathrm{o}} .2$ & $\begin{array}{c}\text { Dezembro } \\
2015\end{array}$ & p.66-75 \\
\hline
\end{tabular}


sujeito assim, segundo Sandel, não estaria em condições de fazer escolhas, pois, é totalmente desvinculado das práticas que prevalecem nas sociedades reais. No mundo real, não podemos libertar-nos dos interesses e lealdades que não só determinam nossas obrigações, mas também estabelecem as nossas identidades ${ }^{14}$. Os liberais pensam ser possível nos libertarmos de nós mesmos e assim, identificar princípios que vão regular nossas vidas em sociedade. Desta forma, em conformidade com princípios justos escolhidos por nós mesmos, viveríamos segundo uma moral que escolhemos ou construímos livremente. O problema levantado por Sandel é o da inadequação da concepção de Rawls de um sujeito moral como um eu totalmente desligado das suas características provenientes da experiência. Seria uma abstração, um sujeito $<<$ radicalmente desincorporado $>>$ o oposto do sujeito <<radicalmente situado $>>$. Fora do mundo da experiência, este sujeito não teria motivação e capacidade para decidir.

Para os comunitaristas, a moralidade é algo que está enraizado nas praticas particulares das comunidades reais. Sandel ataca a asserção fundamental de Rawls de que a comunidade é o produto da associação de indivíduos independentes e de que o valor dessa comunidade deve ser estimado pela justiça dos termos segundo os quais esses indivíduos se associam. Sandel sustenta que não faz sentido pensar numa comunidade com tal modelo, porque, a própria existência de indivíduos capazes de estabelecerem acordos para formarem associações, ou de assentarem nos termos dos acordos, pressupõe a existência de uma comunidade.

\section{Considerações finais}

A teoria da justiça como equidade foi apresentada por John Rawls em 1971, com a publicação da obra A theory of Justice que estabeleceu um novo marco em filosofia política na segunda metade do século XX, no mundo ocidental. Sua teoria parte de um pressuposto ético motivacional, com a pergunta pelas razões para o compromisso enquanto membro de uma comunidade moral, defendendo a tese da cooriginalidade de liberdade (liberty) e igualdade (equality), em uma sociedade marcada pelo pluralismo razoável (reasonable pluralism) de doutrina abrangentes (compreensive doctrines), visando fornecer uma orientação filosófica e moral para as instituições democráticas ${ }^{15}$. Por ser uma teoria coerente, coloca-se como uma alternativa para as sociedades reais o que demonstra serem injustas as acusações sofridas por parte dos libertários e dos comunitaristas. A teoria moral do contrato social é a ideia de que a moralidade consiste em um conjunto de regras que ditam como as pessoas devem tratar umas as outras, regras que pessoas racionais concordarão em aceitar, pois há benefício mútuo, sob a condição de que os outros

\footnotetext{
${ }^{14}$ KUKATHAS, Chandran e PETTIT Philip. Rawls. Uma teoria da justiça e os seus críticos. Lisboa: Gradiva, 2005, p. 116.

15 SILVEIRA, Denis Coitinho. John Rawls Theory of Justice: between liberalism and comunitarism. Trans/Form/Ação, (São Paulo), v.30(1), 2007, p. 187.
}

\begin{tabular}{|c|c|c|c|c|c|}
\hline intuitio & $\begin{array}{c}\text { ISSN } \\
1983-4012\end{array}$ & Porto Alegre & Vol.8 $-\mathrm{N}^{\circ} .2$ & $\begin{array}{c}\text { Dezembro } \\
2015\end{array}$ & p.66-75 \\
\hline
\end{tabular}


também aceitem as mesmas regras. Sociedades políticas na compreensão de Hobbes, Locke, Bentham ou do senso comum do século XX que eles ajudaram a moldar, são conhecidas por associações de indivíduos com o fim de obter benefícios, por meio da ação comum, que eles não poderiam conseguir individualmente. A ação é coletiva, mas sua meta permanece individual ${ }^{16}$. O bem comum é constituído a partir de bens individuais que na soma das práticas sociais, seguindo a fórmula dos princípios de justiça, poderão reverter e beneficiar a todos os membros da sociedade.

No que diz respeito a acusação dos libertários, o discurso não corresponde com os fatos. O maior exemplo foi a crise dos mercados de 2008 que causou um estrago sem precedentes na história econômica do Ocidente, desregulando os mercados e jogando milhões de pessoas para o desemprego. Não fosse a interferência do Estado e a catástrofe teria sido ainda maior. A obra $O$ capital no século XXI (2014) lançada recentemente pelo economista Thomas Piketty, é o mais claro testemunho em favor da teoria de Rawls. A tese de Piketty é de que a taxa privada do retorno do capital é significativamente maior do que a taxa de crescimento dos salários e da produção. Este evento coloca-se então, como uma força desestabilizadora do capitalismo, causando desigualdades e desequilíbrio social e fortalecendo o acúmulo cada vez maior na mão de poucos privilegiados. Esta contradição faz com que poucos investidores acumulem mais capital, desinteressando-se pelas atividades produtivas que geram emprego e distribuição de renda. Os libertários têm pouco a falar sobre justiça social. Com relação à crítica proveniente dos comunitaristas afirmo que não identificamos na teoria da justiça como equidade uma concepção abstrata de pessoa. Na posição original não se utiliza uma concepção metafísica de pessoa ${ }^{17}$. Como a posição original é um artifício de representação, o véu da ignorância não possui características metafísicas sobre a natureza do eu. Não implica um eu ontologicamente anterior aos fatos sobre as pessoas, cujo conhecimento é excluído às partes. Pode-se entrar na posição original a qualquer momento, bastando para tal, argumentar em favor dos princípios de justiça. A crítica de que a sociedade como a proposta por Rawls tem uma concepção individualista de pessoa e tem como característica a atomização social, não procede. O impacto da teoria de Rawls tem resultados reais. Políticos ao redor do mundo citam Rawls para reforçar seus argumentos e juízes referenciam seu trabalho. Alguns de seus conceitos chaves, como por exemplo, o princípio da diferença, já influenciam legisladores na hora de definir qual alteração deve ser feita em política tributária. O princípio da diferença se colocado em prática em um país como o Brasil, tira da gaveta o mofado projeto do imposto progressivo e do imposto sobre grandes fortunas tornando a legislação tributária brasileira mais justa e democrática. $\mathrm{O}$ fato singular do princípio da diferença igualitária, tal como aparece na teoria de Rawls, garantir que os talentos de cada um devam servir à todos indistintamente, ou seja, que faz parte dos recursos que vão beneficiar o conjunto da sociedade como um

\footnotetext{
16 TAYLOR, Charles. Argumentos filosóficos. São Paulo: Edições Loyola, 2000, p. 204.

${ }^{17}$ SILVEIRA, Denis Coitinho. Ensaios sobre ética. Pelotas: Editora e Gráfica Universitária, 2008 , p. 92.
}

\begin{tabular}{|c|c|c|c|c|c|}
\hline intuitio & $\begin{array}{c}\text { ISSN } \\
1983-4012\end{array}$ & Porto Alegre & Vol.8 $-\mathrm{N}^{\mathrm{o}} .2$ & $\begin{array}{c}\text { Dezembro } \\
2015\end{array}$ & p.66-75 \\
\hline
\end{tabular}


todo, mostra que a teoria de Rawls tem alcance comunitário e um alto grau de solidariedade entre os participantes. Na prática, um liberal procedimental como Rawls pode ser um holista, superando desta forma, a questão ontológica da dicotomia atomismo-holismo, escapando da oposição individualismo e coletivismo. Acredito, que sociedades reais, podem se espelhar no artifício da posição original idealizado por Rawls, servindo de parâmetro para a elaboração até mesmo da constituição de um país real. Assegurar a validade dos princípios da justiça em uma sociedade bem-ordenada é plausível à qualquer sociedade que se diz democrática e com senso de justiça. A tradição democrática do Ocidente nos oferece exemplos e iniciativas que oportunizaram consensos substanciais com o propósito de referendar e transferir justiça a todos, indistintamente.

\section{Referências}

BARRY, Brian. The Liberal Theory of Justice. Oxford: Oxford University Press, 1973.

GARGARELLA, Roberto. As teorias da justiça depois de Rawls: um breve manual de filosofia política. São Paulo: WMF Martins Fontes, 2008.

HEGEL, Georg Wilhelm Friedrich. Filosofia do direito. São Leopoldo: Ed. Unisinos, 2010.

Enzyklopädie der philosophischen Wissenschaten III, Werke 10, Frankfurt; Suhrkamp, 1995, § 502.

HOBBES, Thomas. Leviatã ou matéria, forma e poder de um Estado Eclesiástico e civil. São Paulo: Abril, 2000.

KUKATHAS, Chandran; PETTIT Philip. Rawls. Uma teoria da justiça e os seus críticos. Lisboa: Gradiva, 2005.

MILL, John Stuart. Utilitarismo. Coimbra: Biblioteca filosófica, 1961.

MORA, J. Ferrater. Dicionário de Filosofia. São Paulo: Edições Loyola, 2001.

NOZICK, Robert. Anarchy, State and Utopia. Nova Iorque: Basic Books, 1974.

OLIVEIRA, Nythamar Fernandes de. RAWLS. Rio de Janeiro: Zahar Editora, 2003.

PIKETTY, Thomas. O capital no século XXI. Rio de janeiro: Editora Intrínseca, 2014.

RAWLS, John. A theory of justice. Cambridge, Mass: Harvard University Press, 1971.

Political Liberalism. New York: Columbia University Press, 2005.

O liberalismo politico. (Tradução: Álvaro Vita) São Paulo: Martins Fontes, 2011.

Historia da filosofia moral. São Paulo: Martins fontes, 2005.

Justiça e democracia. São Paulo: Martins Fontes, 2002.

Justice as Fairness: A Restatement. E. Kelly (ED). Cambridge: Harvard University Press, 2001.

Conferências sobre a história da filosofia politica. (Org. Samuel Freeman) Tradução: Fabio M. Said. São

Paulo: Martins Fontes, 2012.

Uma teoria da justiça. São Paulo: Martins Fontes, 2002.

SANDEL, Michael. Liberalism and the Limits of Justice. Cambridge: Cambridge University Press, 1982.

SILVEIRA, Denis Coitinho. John Rawls Theory of Justice: between liberalism and comunitarism. Trans/Form/Ação, (São Paulo), v.30(1), 2007, p. 169-190.

Ensaios sobre ética. Pelotas: Editora e Gráfica Universitária, 2008.

TAYLOR, Charles. As fontes do self - A construção da identidade moderna. São Paulo: Edições Loyola, 1997. Argumentos filosóficos. São Paulo: Edições Loyola, 2000.

Recebido em: 17/09/2014

Aprovado para a publicação em: 11/11/2015

\begin{tabular}{|c|c|l|l|c|c|}
\hline intuitio & $\begin{array}{c}\text { ISSN } \\
1983-4012\end{array}$ & Porto Alegre & Vol.8 $-\mathrm{N}^{\mathrm{o}} .2$ & $\begin{array}{c}\text { Dezembro } \\
2015\end{array}$ & p.66-75 \\
\hline
\end{tabular}

